\title{
PENGARUH KUALITAS KEHIDUPAN KERJA, MOTIVASI KERJA, DAN PENGEMBANGAN KARIR TERHADAP KEPUASAN KERJA PEGAWAI DI KANTOR CAMAT KOTA ADMINISTRASI JAKARTA BARAT
}

\author{
M. Ifran Sanni*1), Silvia Norita ${ }^{2)}$ Isrial $^{3)}$ \\ ${ }^{1,3}$ Dosen Universitas Raharja, ${ }^{2}$ Program Studi Manajemen Fakultas Universitas Mercubuana \\ 1ifran@raharja.info, ${ }^{3}$ isrial@raharja.info
}

\begin{abstract}
Abstrak
Penelitian ini bertujuan mengetahui pengaruh kualitas kehidupan kerja, motivasi kerja, dan pengembangan karir terhadap kepuasan kerja pegawai di Kantor Camat Kota Administrasi Jakarta Barat. Penelitian menggunakan metode survey dengan penelitian kausalitas dan deskriftif dengan metode pengumpulan data melalui metode riset lapangan, studi kepustakaan dan menggunakan instrumen kuesioner. Responden penelitian adalah pegawai di Kantor Camat Kota Administrasi Jakarta Barat yang berjumlah 158 orang. Hasil penelitian menunjukkan bahwa hanya motivasi kerja yang berpengaruh positif dan signifikan terhadap kepuasan kerja pegawai, sementara kualitas kehidupan kerja dan pengembangan karir tidak. Berdasarkan analisis korelasi antar dimensi, dimensi kebutuhan akan prestasi pada variabel motivasi kerja memiliki korelasi paling kuat terhadap dimensi rekan kerja pada variabel kepuasan kerja. Kualitas kehidupan kerja, motivasi kerja dan pengembangan karir berpengaruh secara simultan terhadap kepuasan kerja pegawai di Kantor Camat Kota Administrasi Jakarta Barat.
\end{abstract}

Kata kunci: Kepuasan Kerja, Pengembangan Karir, Motivasi Kerja, Kualitas Kehidupan Kerja

\begin{abstract}
This study aims to determine the effect the quality of working life, motivation and career development on employee satisfaction at the Head Office of West Jakarta Administration. The study used survey method with causality research and descriptive data collection method through field research methods, the study of literature and using the questionnaire. Respondents were employees at Head Office West Jakarta Administration totaling 158 people. The results showed that the only motivation positive and significant impact on job satisfaction of employees, while the quality of work life and career development not. Based on the analysis of the correlation between dimensions, dimensions of need for achievement in work motivation variable has the strongest correlation to the dimensions of colleagues on job satisfaction variables.The quality of working life, motivation and career development simultaneous effect on job satisfaction of employees at Head Office West Jakarta Administration.
\end{abstract}

Keywords: quality of working life, work motivation, career development, job satisfaction

\section{Pendahuluan}

Sumber daya manusia di dalam suatu organisasi memegang peranan yang sangat penting. Potensi setiap sumber daya manusia yang ada dalam organisasi harus dapat dimanfaatkan sebaik-baiknya, sehingga mampu memberikan hasil yang maksimal. Pegawai negeri sipil atau aparatur sipil negara sebagai unsur aparatur negara, abdi negara dan abdi masyarakat saat ini dituntut untuk dapat bekerja dengan lebih baik mengingat berbagai fenomena perubahan lingkungan strategis yang sangat dinamis terjadi di era globalisasi. Pegawai dapat bekerja 
dengan baik sesuai yang diinginkan masyarakat apabila pegawai merasa puas dengan apa yang diperoleh dan dirasakan dalam pekerjaannya. Pegawai yang tidak merasakan kepuasan kerja tidak akan pernah mencapai kepuasan psikologis dan akhirnya akan timbul sikap maupun tingkah laku negatif. Sebaliknya pegawai yang merasakan kepuasan kerja akan dapat bekerja dengan baik, penuh semangat, aktif dan dapat berprestasi lebih baik dalam memberikan pelayanan dibanding pegawai yang tidak puas dalam pekerjaannya.

Kecamatan yang merupakan salah satu perangkat daerah di Pemerintah Provinsi DKI Jakarta juga merasakan dampak dari reformasi birokrasi. Adanya perampingan struktur organisasi dengan menghilangkan 2 jabatan kepala seksi, yang sebelumnya berjumlah 5 kepala seksi, jabatan-jabatan struktural yang diisi oleh pejabat-pejabat baru hasil seleksi jabatan, diikuti dengan rotasi staf secara besar-besaran. Beberapa pejabat struktural ditempatkan pada posisi jabatan yang tidak sesuai dengan latar belakang pendidikan dan pengalaman kerja. Sebagian besar staf kecamatan terdiri dari pegawai yang sebelumnya pernah menduduki jabatan struktural eselon IV seperti para wakil lurah, kepala seksi kecamatan dan kelurahan, tetapi mereka dinyatakan tidak lolos seleksi sehingga tidak lagi menduduki jabatan. Sebagian besar dari para staf ini telah memiliki masa kerja yang lama, meniti karir dari bawah dan ketika telah menduduki jabatan, mereka dihadapkan pada kenyataan kehilangan jabatan dan kembali menjadi staf. Kondisi-kondisi tersebut tentu berdampak pada kepuasan kerja pegawai. Untuk mengetahui tingkat kepuasan kerja pegawai kecamatan di Jakarta Barat, peneliti telah melakukan survey pendahuluan terhadap 20 orang pegawai dari 2 kecamatan yaitu Kecamatan Tambora dan Kebon Jeruk. Survey dilakukan dengan memakai pendekatan single global rating yaitu hanya bertanya pada setiap individu untuk memberikan respon terhadap pertanyaan, seperti: "Semua hal dipertimbangkan, seberapa puaskah anda dengan pekerjaan anda?". Responden kemudian menjawab dengan melingkari bulatan antara $1-5$ (dari sangat puas sampai sangat tidak puas) (Robbins, 2006: 101). Hasil survey pendahuluan sebagai berikut:

\begin{tabular}{lrr}
\multicolumn{3}{c}{ Tabel 1. Survey Pendahuluan Kepuasan Kerja } \\
\hline \multicolumn{1}{c}{ Kategori } & Jumlah & Persentase \\
\hline Sangat Puas & - & - \\
Puas & 5 & 25 \\
Cukup Puas & 2 & 10 \\
Tidak Puas & 13 & 65 \\
Sangat Tidak Puas & - & - \\
Total & $\mathbf{2 0}$ & $\mathbf{1 0 0}$ \\
\hline
\end{tabular}

Sumber : Hasil Survey Pendahuluan (2021)

Hasil di atas menunjukkan bahwa kepuasan kerja pegawai 2 kecamatan di Jakarta Barat cenderung rendah, mencapai angka $65 \%$ atau 13 orang responden. Hanya 5 orang atau $25 \%$ dari reponden yang merasa puas dengan pekerjaannya dan 2 orang atau $10 \%$ yang merasa cukup puas. 
Tabel 2. Pelatihan dan Pendidikan Pegawai Tahun 2014

\begin{tabular}{clrr}
\hline No & \multicolumn{1}{c}{ Nama Diklat } & Jumlah & ( Jumlah Pegawai 169 orang) \\
\hline 1. & Pelayanan Prima & 3 & $5.07 \%$ \\
\hline 2. & Manajemen SDM & 2 & $3.38 \%$ \\
\hline 3. & Pengadaan Barang dan Jasa & 3 & $5.07 \%$ \\
\hline 4. & Bendahara Pengeluaran & 3 & $5.07 \%$ \\
\hline & Jumlah & $\mathbf{1 1}$ & $\mathbf{1 8 . 5 9 \%}$
\end{tabular}

Sumber: Kantor Kepegawaian Kota Administrasi Jakarta Barat Tahun 2014

Pada tabel 2 memperlihatkan bahwa pelatihan dan pendidikan hanya diikuti oleh $18.59 \%$ pegawai. Hal ini menunjukan bahwa masih kurangnya pelatihan dan pendidikan yang diperlukan untuk meningkatkan pengembangan karir pegawai. Ketidakjelasan pengembangan karir ini juga berpengaruh pada kepuasan kerja pegawai. Rivai (2014:264) menyatakan bahwa pengembangan karir merupakan alat terpenting bagi manajemen untuk meningkatkan produktivitas, sikap terhadap pekerjaan serta kepuasan kerja.

Uraian di atas menjadi perhatian bagi peneliti untuk melakukan penelitian tentang kepuasan kerja dilihat dari variabel kualitas kehidupan kerja, motivasi kerja dan pengembangan karir. Ketiga variabel tersebut, akan diteliti sehingga nantinya bisa mengidentifikasi variabel mana yang paling berpengaruh terhadap kepuasan kerja pegawai atau secara bersama-sama saling mempengaruhi kepuasan kerja pegawai dan perlu ditangani dengan serius, maka dilakukan penelitian dengan judul:“ Pengaruh Kualitas Kehidupan Kerja, Motivasi Kerja dan Pengembangan Karir terhadap Kepuasan Kerja Pegawai di Kantor Camat Kota Administrasi Jakarta Barat”.

\section{Rumusan Masalah}

Berdasarkan penjelasan pada latar belakang masalah, maka diperoleh perumusan masalah penelitian sebagai berikut :

a. Apakah kualitas kehidupan kerja berpengaruh terhadap kepuasan kerja pegawai?

b. Apakah motivasi kerja berpengaruh terhadap kepuasan kerja pegawai ?

c. Apakah pengembangan karir berpengaruh terhadap kepuasan kerja pegawai ?

d. Apakah kualitas kehidupan kerja, motivasi kerja dan pengembangan karir secara simultan berpengaruh terhadap kepuasan kerja pegawai ?

\section{Kajian Teori}

\section{Kepuasan Kerja}

Davis yang dikutip oleh Mangkunegara (2008:117) yang mengemukakan bahwa "Job satisfaction is the favorableness or unfavorableness with employees view their work", artinya bahwa kepuasan kerja adalah perasaan menyokong atau tidak menyokong yang dialami pegawai dalam bekerja. 


\section{Kualitas Kehidupan Kerja}

Dubrin dalam Simanungkalit (2012:17) menyatakan bahwa kualitas kehidupan kerja dapat diartikan sebagai derajat pemenuhan kebutuhan manusia (human needs) dalam suatu lingkungan kerja. Apabila kebutuhan manusia telah dipenuhi, maka produktivitas organisasi dapat meningkat. Keterlibatan antara karyawan dan atasan akan membentuk kualitas kehidupan kerja. Luthans (2006:569) menyatakan bahwa kualitas kehidupan kerja adalah dampak efektivitas manusia dan perusahaan yang dikombinasikan dengan penekanan partisipasi dalam pemecahan masalah dan pembuatan keputusan.

\section{Motivasi Kerja}

Menurut Hasibuan (2008:141) motivasi adalah pemberian daya penggerak yang menciptakan kegairahan kerja seseorang agar mereka mau bekerja sama, bekerja efektif, dan terintegrasi dengan segala daya upayanya untuk mencapai kepuasan. Luthans (2006:161) memandang motivasi sebagai suatu sistem yang terdiri dari:

1. Kebutuhan

Kebutuhan diciptakan setiap kali ada ketidakseimbangan psikologis dan fisiologis.

2. Dorongan

Pendorong atau motif yang dibentuk untuk mengurangi kebutuhan.

3. Insentif

Pada akhir siklus motivasi adalah insentif, yang didefinisikan sebagai sesuatu yang akan meringankan kebutuhan dan mengurangi adanya dorongan.

\section{Pengembangan Karir}

Menurut Simamora (2004: 392), karir adalah urutan aktivitas-aktivitas yang berkaitan dengan pekerjaan dan perilaku-perilaku, nilai-nilai, dan aspirasi seseorang selama rentang hidup orang tersebut.

\section{Metode}

Desain penelitian yang dilakukan adalah explanatory research yaitu penelitian yang bertujuan menjelaskan kausal antara variabel-variabel melalui pengujian hipotesis. Jenis desain ini biasa disebut dengan desain kausal atau desain pengujian hipotesis, yaitu studi yang termasuk menjelaskan hubungan tertentu atau menentukan perbedaan antar kelompok atau kebebasan (independensi) dua atau lebih faktor dalam suatu situasi ( Istijanto, 2008:21, Sekaran, 2009:162, Umar, 2013:10-11).

Data yang digunakan dalam penelitian ini adalah data primer dan data sekunder. Data Primer merupakan data penelitian yang diperoleh secara langsung dari sumber asli (tidak melalui perantara). Data primer yang peneliti gunakan adalah data primer yang bersifat kuantitatif. Data kuantitatif polanya bersifat terstruktur sehingga mudah dibaca peneliti. Data primer secara khusus dikumpulkan oleh peneliti untuk menjawab penelitian atau berhubungan langsung dengan permasalahan penelitian atau berhubungan langsung dengan permasalahan yang diteliti. 
Data Sekunder yaitu data yang didapat peneliti secara tidak langsung melalui media perantara (diperoleh dan dicatat oleh pihak lain). Data ini diperoleh melalui literatur, jurnal dan sumber-sumber yang mendukung penelitian ini. Data sekunder umumnya berupa bukti, catatan atau laporan historis yang telah disusun dalam arsip (data dokumentasi) yang dipublikasikan dan yang tidak dipublikasikan yang berguna sebagai tambahan argumen logis (Istijanto, 2008:32). Pegawai sebagai responden adalah sumber data primer untuk penelitian ini. Data sekunder peneliti dapatkan dari laporan-laporan kecamatan, dan datadata pendukung lainnya.

\section{Hasil Dan Pembahasan}

Penelitian dilakukan di Kantor Camat Kota Administrasi Jakarta Barat yang terdiri dari 8 kecamatan yaitu Kebon Jeruk, Kembangan, Cengkareng, Kalideres, Grogol Petamburan, Palmerah, Tambora, dan Taman Sari. Pada penelitian ini total populasi sebesar 169 responden. Penelitian mengambil sampel $100 \%$ dari total populasi yakni sebesar 169 responden. Kuesioner kemudian disebar ke seluruh responden. Dari 169 kuesioner yang disebar data yang terkumpul atau kembali sebesar 158 kuesioner dari waktu yang sudah ditentukan.

\section{a. Uji Validitas}

Tabel 3. Hasil Uji Validitas Instrumen Penelitian

\begin{tabular}{|c|c|c|c|c|}
\hline Variabel & Item & $\mathbf{r}_{\text {hitung }}$ & $\mathbf{r}_{\text {tabel }}$ & Keputusan \\
\hline \multirow{16}{*}{$\begin{array}{c}\text { Kualitas Kehidupan } \\
\text { Kerja }\left(\mathrm{X}_{1}\right)\end{array}$} & Q1 & 0,239 & \multirow{16}{*}{0,1562} & \multirow{16}{*}{$\begin{array}{c}\text { Valid Nilai } \\
\mathrm{r}_{\text {hitung }}>\mathrm{r}_{\text {tabel }} \\
\text { pada } \mathrm{N}= \\
158\end{array}$} \\
\hline & Q2 & 0,362 & & \\
\hline & Q3 & 0,248 & & \\
\hline & Q4 & 0,724 & & \\
\hline & Q5 & 0,386 & & \\
\hline & Q6 & 0,229 & & \\
\hline & Q7 & 0,506 & & \\
\hline & Q8 & 0,518 & & \\
\hline & Q9 & 0,512 & & \\
\hline & Q10 & 0,514 & & \\
\hline & Q11 & 0,534 & & \\
\hline & Q12 & 0,724 & & \\
\hline & Q13 & 0,311 & & \\
\hline & Q14 & 0,537 & & \\
\hline & Q15 & 0,334 & & \\
\hline & Q16 & 0,334 & & \\
\hline \multirow{8}{*}{ Motivasi Kerja $\left(\mathrm{X}_{2}\right)$} & Q1 & 0,652 & \multirow{8}{*}{0,1562} & \multirow{8}{*}{$\begin{array}{c}\text { Valid Nilai } \\
\mathrm{r}_{\text {hitung }}>\mathrm{r}_{\text {tabel }} \\
\text { pada } \mathrm{N}= \\
158\end{array}$} \\
\hline & Q2 & 0,443 & & \\
\hline & Q3 & 0,627 & & \\
\hline & Q4 & 0,578 & & \\
\hline & Q5 & 0,285 & & \\
\hline & Q6 & 0,651 & & \\
\hline & Q7 & 0,627 & & \\
\hline & Q8 & 0,465 & & \\
\hline
\end{tabular}




\begin{tabular}{|c|c|c|c|c|}
\hline & \multirow{2}{*}{$\begin{array}{c}\text { Q9 } \\
\text { Q10 }\end{array}$} & 0,578 & & \\
\hline & & 0,652 & & \\
\hline & Q11 & 0,520 & & \\
\hline & Q12 & 0,651 & & \\
\hline \multirow{10}{*}{$\begin{array}{l}\text { Pengembangan Karir } \\
\left(\mathrm{X}_{3}\right)\end{array}$} & Q1 & 0,778 & \multirow{10}{*}{0,1562} & \multirow{10}{*}{$\begin{array}{c}\text { Valid Nilai } \\
\mathrm{r}_{\text {hitung }}>\mathrm{r}_{\text {tabel }} \\
\text { pada } \mathrm{N}= \\
158\end{array}$} \\
\hline & Q2 & 0,648 & & \\
\hline & Q3 & 0,750 & & \\
\hline & Q4 & 0,778 & & \\
\hline & Q5 & 0,387 & & \\
\hline & Q6 & 0,750 & & \\
\hline & Q7 & 0,778 & & \\
\hline & Q8 & 0,648 & & \\
\hline & Q9 & 0,750 & & \\
\hline & Q10 & 0,648 & & \\
\hline \multirow[t]{15}{*}{ Kepuasan Kerja (Y) } & Q1 & 0,547 & \multirow{15}{*}{0,1562} & \multirow{15}{*}{$\begin{array}{c}\text { Valid Nilai } \\
\mathrm{r}_{\text {hitung }}>\mathrm{r}_{\text {tabel }} \\
\text { pada } \mathrm{N}= \\
158\end{array}$} \\
\hline & Q2 & 0,664 & & \\
\hline & Q3 & 0,614 & & \\
\hline & Q4 & 0,571 & & \\
\hline & Q5 & 0,704 & & \\
\hline & Q6 & 0,693 & & \\
\hline & Q7 & 0,547 & & \\
\hline & Q8 & 0,664 & & \\
\hline & Q9 & 0,614 & & \\
\hline & Q10 & 0,571 & & \\
\hline & Q11 & 0,704 & & \\
\hline & Q12 & 0,693 & & \\
\hline & Q13 & 0,664 & & \\
\hline & Q14 & 0,435 & & \\
\hline & Q15 & 0,397 & & \\
\hline
\end{tabular}

Sumber : Hasil olah data primer (2021)

Berdasarkan tabel 3 terlihat semua item pernyataan dalam kuesioner sudah memenuhi syarat valid, yaitu nilai $r_{\text {hitung }}>r_{\text {tabel }}$. Kesimpulan dari uji validitas yaitu instrumen yang digunakan dapat dilanjutkan untuk membahas permasalahan dalam penelitian ini.

\section{b. Uji Reliabilitas}

Metode pengujian reliabilitas instrumen menggunakan rumus korelasi Cronbach Alpha, dengan ketentuan nilai $\alpha>0,6$.

Tabel 4. Hasil Reliabilitas Instrumen Penelitian

\begin{tabular}{lcc}
\hline \multicolumn{1}{c}{ Variabel } & A & Keputusan \\
\hline $\begin{array}{l}\text { Kualitas Kehidupan Kerja } \\
\left(\mathrm{X}_{1}\right)\end{array}$ & 0,721 & Reliabel Nilai $\alpha>0,6$ \\
Motivasi Kerja $\left(\mathrm{X}_{2}\right)$ & 0,803 & Reliabel Nilai $\alpha>0,6$ \\
Pengembangan Karir $\left(\mathrm{X}_{3}\right)$ & 0,880 & Reliabel Nilai $\alpha>0,6$
\end{tabular}


Kepuasan Kerja (Y)

Sumber: Hasil olah data primer (2021)

Berdasarkan Tabel 4 terlihat semua item pernyataan dalam kuesioner sudah memenuhi syarat reliabel nilai $\alpha>0,6$. Kesimpulan dari uji realibilitas yaitu instrumen yang digunakan dapat dilanjutkan untuk membahas permasalahan dalam penelitian ini.

\section{Uji Asumsi Klasik}

\section{Uji Normalitas}

Berdasarkan hasil uji Kolmogorov-Sminorv menunjukkan bahwa nilai sig 0,417 , nilai sig tersebut lebih besar dari $>0.05$, maka keempat variabel tersebut dinyatakan normal.

\section{Uji Multikolinearitas}

Hasil uji multikolinieritas dapat dilihat pada tabel di bawah ini.

Tabel 5. Uji Multikolinieritas

\begin{tabular}{lcc}
\hline \multicolumn{1}{c}{ Variabel } & Tolerance & VIF \\
\hline Kualitas Kehidupan Kerja &, 303 & 3,305 \\
Motivasi Kerja &, 212 & 4,721 \\
Pengembangan Karir &, 342 & 2,922 \\
\hline
\end{tabular}

Sumber: Hasil olah data primer (2021)

Hasil output data didapatkan bahwa semua nilai Tolerance $>\mathbf{0 , 1}$ dan angka VIF $<\mathbf{1 0}$ ini berarti tidak terjadi multikolinieritas dan menyimpulkan bahwa uji multikolinieritas terpenuhi.

\section{Uji Hesteroskedastisitas}

\begin{tabular}{ll}
\multicolumn{2}{c}{ Tabel 6. Uji Heteroskedastisitas } \\
\hline \multicolumn{1}{c}{ Variabel } & Sig \\
\hline Kualitas Kehidupan Kerja &, 970 \\
Motivasi Kerja &, 097 \\
Pengembangan Karir &, 521 \\
\hline
\end{tabular}

Sumber: Hasil olah data primer (2021)

Berdasarkan tabel di atas, dapat diperoleh hasil bahwa korelasi rank spearman antara variabel kualitas kehidupan kerja, motivasi kerja, pengembangan karir dengan kepuasan kerja lebih besar dari 0.05, maka masalah heterokesatisitas dapat dikatakan tidak terjadi.

\section{Analisis Regresi Linier Berganda}

\section{a. Uji Model}

Tabel 7. Uji Model

\begin{tabular}{|c|c|c|c|c|}
\hline $\mathbf{R}$ & R Square & Adjusted R Square & $\mathbf{F}$ & Sig \\
\hline, $768^{\mathrm{a}}$ & ,590 & ,582 &, 73.962 &, 000 \\
\hline
\end{tabular}


Sumber : Hasil olah Data Primer (2021)

1. Analisis Koefisien Determinasi

Dari Tabel 7 nilai R Square menunjukkan bahwa 59,0 \% dari varian kualitas kehidupan kerja, motivasi kerja dan pengembangan karir dapat dijelaskan oleh perubahan dalam variabel kepuasan kerja, sisanya 41,0\% dipengaruhi oleh variabel lain.

2. Uji F

Dari Tabel 5.13. dapat dilihat bahwa nilai Sig adalah $0,000<0,05$, nilai $\mathrm{f}_{\text {hitung }}$ adalah 73,962 dan $\mathrm{f}_{\text {tabel }}$ adalah 2,66 dengan demikian $\mathrm{F}$ hitung $>\mathrm{F}$ tabel yaitu 73,96>2,66. Hal ini berarti hipotesis secara silmutan variabel bebas mempunyai pengaruh terhadap variabel terikat.

\section{b. Uji Pengaruh Variabel Bebas terhadap Variabel Terikat}

Tabel 8.

Uji Pengaruh Kualitas Kehidupan Kerja, Motivasi Kerja, dan Pengembangan Karir terhadap Kepuasan Kerja

\begin{tabular}{lccc}
\hline \multicolumn{1}{c}{ Variabel } & B & t & Sig \\
\hline (Constant) &, 604 & 1,972 &, 050 \\
Kualitas Kehidupan Kerja &, 090 &, 847 &, 398 \\
Motivasi Kerja &, 758 & 7,584 &, 000 \\
Pengembangan Karir & -002 & -030 &, 976 \\
\hline Dependent Variabel : Kepuasan Kerja & & \\
\hline \multicolumn{2}{l}{ Sumber: Hasil olah data primer (2021) }
\end{tabular}

1. Analisis Koefisien Regresi

Berdasarkan Tabel 5.14. diperoleh persamaan garis regresi sebagai berikut:

$\mathbf{Y}_{4}=\mathbf{a}+\mathbf{b}_{1} \mathbf{X}_{1}+\mathbf{b}_{2} \mathbf{X}_{2}+\mathbf{b}_{3} \mathbf{X}_{3}+\mathbf{e}$

$Y_{4}=0,604+0,090 X_{1}+0,758 X_{2}+(-0,002) X_{3}+e$

Akan tetapi nilai-nilai probabilitas Sig. untuk variabel kualitas kehidupan kerja dan pengembangan karir di atas 0,05 atau $5 \%$ sehingga tidak signifikan. Hanya variabel motivasi kerja yang signifikan karena mempunyai nilai Sig $<0,05$.

\section{Uji t}

Berdasarkan Tabel 5.14. variabel kualitas kehidupan kerja dan pengembangan karir memilki nilai thitung < ttabel $(1,165)$ sehingga tidak memilki pengaruh positif dan signifikan terhadap variabel kepuasan kerja. Hanya variabel motivasi kerja yang memiliki pengaruh positif dan signifikan karena memiliki nilai thitung $>$ ttabel.

\section{Analisis Matrik Korelasi Antar Dimensi}

Analisa matrik korelasi antar dimensi variabel ditujukan untuk mengetahui korelasi antar dimensi variabel bebas terhadap dimensi variabel terikat. Tabel di bawah ini menunjukkan korelasi dimensi antar variabel motivasi kerja dan kepuasan kerja. 
Tabel 9. Matrik Korelasi Antar Dimensi

\begin{tabular}{|c|c|c|c|c|c|c|}
\hline & Variabel & & & epuasan Kerja & $(\mathrm{Y})$ & \\
\hline Variabel & Dimensi & $\begin{array}{l}\text { Pekerjaan } \\
\text { itu sendiri } \\
\quad(\mathrm{Y} 1)\end{array}$ & $\begin{array}{l}\text { Gaji } \\
\text { (Y2) }\end{array}$ & $\begin{array}{c}\text { Kesempatan } \\
\text { Promosi } \\
\text { (Y3) }\end{array}$ & $\begin{array}{c}\text { Pengawasan } \\
\text { (Y4) }\end{array}$ & $\begin{array}{l}\text { Rekan } \\
\text { Kerja } \\
\text { (Y5) } \\
\end{array}$ \\
\hline \multirow{3}{*}{$\begin{array}{c}\text { Motivasi } \\
\text { Kerja } \\
\text { (X2) }\end{array}$} & $\begin{array}{l}\text { Kebutuhan akan } \\
\text { Prestasi (X2.1) }\end{array}$ &, 863 & ,896 & ,863 & ,896 & 903 \\
\hline & $\begin{array}{c}\text { Kebutuhan akan } \\
\text { Kekuasaan } \\
(\mathrm{X} 2.2) \\
\end{array}$ &, 524 & ,283 & ,524 & ,283 & ,484 \\
\hline & $\begin{array}{c}\text { Kebutuhan } \\
\text { untuk Berafiliasi } \\
(\mathrm{X} 2.3)\end{array}$ & ,319 & ,560 & ,319 &, 560 & ,358 \\
\hline
\end{tabular}

Sumber: Hasil olah Data Primer (2021)

Berdasarkan Tabel 5.17 Matrik Korelasi Antar Dimensi di atas, dapat diketahui bahwa korelasi antar dimensi-dimensi pada variabel motivasi kerja (X2) dengan dimensi-dimensi pada variabel kepuasan kerja (Y) menunjukkan:

1. Untuk dimensi kebutuhan akan prestasi (X2.1) mempunyai hubungan yang sangat kuat terhadap dimensi-dimensi variabel kepuasan kerja karena memiliki nilai koefisien $0,80-1,000$, dan dimensi yang memiliki hubungan sangat kuat adalah pada dimensi rekan kerja (Y5), dengan nilai koefisien 0,903 .

2. Untuk dimensi kebutuhan akan kekuasaan (X2.2) mempunyai hubungan rendah dan sedang terhadap dimensi-dimensi kepuasan kerja (Y), karena memiliki nilai koefisien 0,20 - 0,399 dan 0,40-0,599

3. Untuk dimensi kebutuhan untuk berafiliasi (X2.3) juga memiliki hubungan rendah dan sedang terhadap dimensi-dimensi kepuasan kerja (Y)

\section{Kesimpulan}

Setelah dilakukan pengujian atas hipotesis dan analisis korelasi antar dimensi maka dapat diambil kesimpulan sebagai berikut:

1) Kualitas kehidupan kerja tidak berpengaruh positif dan signifikan terhadap kepuasan kerja pegawai di Kantor Camat Kota Administrasi Jakarta Barat.

2) Motivasi kerja berpengaruh positif dan signifikan terhadap kepuasan kerja pegawai di Kantor Camat Kota Administrasi Jakarta Barat. Artinya, akan terjadi peningkatan kepuasan kerja pada pegawai apabila ada peningkatan motivasi kerja. Korelasi antar dimensi yang paling berhubungan adalah dimensi kebutuhan akan prestasi terhadap variabel kepuasan kerja pada dimensi rekan kerja (memiliki hubungan "sangat kuat").

3) Pengembangan karir tidak berpengaruh positif dan signifikan terhadap kepuasan kerja pegawai di Kantor Camat Kota Administrasi Jakarta Barat.

4) Kualitas kehidupan kerja, motivasi kerja dan pengembangan karir secara simultan berpengaruh positif dan siginifikan terhadap kepuasan kerja pegawai terutama variabel motivasi kerja, karena dengan motivasi kerja yang tinggi 
dan didukung oleh kualitas kehidupan kerja yang baik serta pengembangan karir yang sesuai maka akan meningkatkan kepuasan kerja.

\section{Saran}

Berdasarkan kesimpulan yang diperoleh maka saran dan rekomendasi yang dapat diberikan adalah sebagai berikut:

1) Dimensi motivasi kerja yang paling berpengaruh adalah dimensi kebutuhan akan prestasi terhadap kepuasan kerja. Oleh karena itu disarankan agar Pemerintah Provinsi DKI Jakarta dapat memberikan umpan balik bagi para pegawainya sebagai bentuk pengakuan atas prestasi mereka. Salah satu bentuk umpan balik bagi pegawai yang berprestasi adalah promosi jabatan. Pegawai yang dianggap bagus kinerjanya atau yang mendapatkan prestasi seperti menang lomba penilaian kebersihan wilayah, pengumpul PBB atau ZIS terbanyak, lomba kinaerja camat dan lurah, biasanya mendapatkan kesempatan untuk promosi jabatan. Akan tetapi dengan diterapkannya sistem seleksi terbuka untuk promosi jabatan, prestasi kerja saja tidak cukup karena seorang pegawai harus lulus seleksi terbuka untuk mendapatkan promosi jabatan. Untuk itu disarankan agar Pemerintah Provinsi DKI Jakarta dapat menerapkan sistem seleksi terbuka yang juga memperhatikan prestasi kerja pegawai, sehingga mendorong pegawai untuk tetap berprestasi yang nantinya akan meningkatkan kepuasan kerja mereka.

2) Dimensi motivasi kerja yang paling berpengaruh adalah kebutuhan akan prestasi terhadap dimensi rekan kerja dari variabel kepuasan kerja. Dapat diambil kesimpulan bahwa motivasi untuk berprestasi seorang pegawai sangat tergantung pada rekan kerjanya. Hal ini berarti bahwa untuk mencapai suatu prestasi yang nantinya akan menyebabkan kepuasan kerja diperlukan suatu kerjasama yang baik antar sesama pegawai atau diperlukan adanya kerja kelompok (team work). Oleh karena itu diperlukan peran pemimpin dalam hal ini camat agar dapat menciptakan suasana kerja kondusif yang mengedepankan peran kerja kelompok dari para bawahannya. Kenyataan yang terjadi, masih ada pemimpin yang tidak bisa membentuk suatu "team work" yang kuat di tempat kerjanya. Terlalu fokus pada penyelesaian masalah di wilayah sehingga mengabaikan pembinaan internal para pegawainya. Pembagian kerja belum optimal, beban kerja banyak diberikan kepada para pegawai yang masih muda karena menguasai teknologi dan dianggap lebih mampu membantu penyelesaian masalah di wilayah. Untuk meningkatkan kepuasan kerja pegawai disarankan agar para pemimpin dapat menciptakan suasana kerja yang mendukung kerjasama yang baik antara pegawai dengan rekan kerjanya. Beban kerja hendaknya dibagi sesuai dengan kemampuan. Pegawai yang masih muda memang lebih menguasai teknologi, tetapi pegawai senior lebih unggul dalam pengalaman kerja sehingga jika mereka dapat menjalin kerjasama dengan baik maka akan tercapai prestasi kerja yang memuaskan.

3) Dimensi motivasi kerja yang juga kuat pengaruhnya adalah dimensi kebutuhan akan prestasi terhadap dimensi gaji dan pengawasan pada variabel kepuasan kerja. Oleh karena itu disarankan agar sistem penggajian yang diterapkan dapat mendukung kebutuhan prestasi pegawai. Selain itu juga 
sangat diperlukan peran pengawas dalam hal ini pimpinan kantor untuk dapat mendorong pencapaian prestasi para pegawainya.

4) Peneliti yang ingin melakukan penelitian tentang kepuasan kerja pegawai hendaknya menambahkan faktor-faktor lain seperti: gaya kepemimpinan, budaya organisasi, kompetensi. Penelitian juga dapat dikaitkan dengan teoriteori motivasi lainnya seperti teori penguatan, teori keadilan dan teori harapan. Hal ini penting sebab melihat adanya hasil yang positif dari teori motivasi McClelland terhadap kepuasan kerja, sehingga kedepannya akan diperoleh pengaruh teori motivasi yang komprehensif dalam mempengaruhi kepuasan kerja.

\section{Daftar Pustaka}

Amin, Zulkarnain. (2013). "Quality of Work Life in Indonesian Public Service Organizations: The Role of Career Development and Personal Factors". International Journal of Applied Psychology, Vol. 3 No. 3. pp: 38-44

Aryansyah, Imam dan Erika S. Kusumaputri. (2013). "Iklim Organisasi dan Kualitas Kehidupan Kerja Karyawan”. Jurnal Humanitas, Vol. X No.1. pp:75-86.

Cascio. (2006). Managing Human Resources, Productivity, Quality of Work Life, Profit. New York, Mc. Graw. Hill.

Chooran, Shirazi dan M. Reza Azadehdel. (2021). "Quality of Work Life and Its Role in Job Satisfaction of Organizational Managers: (The Case of Managers in Alborz Insurance Company's Branches)". Cumhuriyet University Faculty of Science Journal, Vol. 36 No. 3. pp:258-266.

Duyan, E.C, Akyildiz dan Darren Van Laar. (2013). "Measuring Work Related Quality of Life and Affective Well-Being in Turkey". Mediterranean Journal of Social Sciences, Vol. 4 No.1.pp: 105-116.

Fanimehin, O Adebayo dan S.O Popoola. (2013). "Effect of Career Progresion, Work Motivation, and Leadership Style on Job Satisfaction of Library Personnel in The Federal Civil Service of Nigeria". International Journal of Library and Information Science, Vol. 5.pp:147-159.

Hasibuan, Malayu SP. (2007). Manajemen Sumber Daya Manusia. Jakarta: PT. Bumi Aksara.

Istijanto Oei. (2010). Riset Sumber Daya Manusia: Cara Praktis Mengukur Stres, Kepuasan Kerja, Komitmen, Loyalitas, Motivasi Kerja \& Aspek-aspek Kerja Karyawan Lainnya. Gramedia Pustaka Utama. Jakarta.

Luthans, Fred. (2006). Perilaku Organisasi. Edisi Terjemahan. Yogyakarta: Penerbit Andi

Mangkunegara, A.A. Anwar Prabu. (2011). Manajemen Sumber Daya Manusia Perusahaan. Remaja Rosdakarya. Bandung.

Mafini, Chengedzai dan Nobukhosi Diodio. (2014). "The Relationship Between Extrinsic Motivation, Job Satisfaction and Life Satisfaction Among Employees in a Public Organization". Departemen of Marketing Vaal University of Technology South Africa, Vol 2. pp: 1-13.

Mohammadi, Heydar dan Mohsen Ameri Shahrabi. (2013). "A Study on Relationship between Quality of Work Life and Job Satisfaction". Management Science Letters, Vol. 3. pp: 2675-2680. 
Nekouei, H Mohammad, Mumtazah BT Othman, Jariah Bt Masud dan Aminah Bt Ahmad. (2014). "Quality of Work Life and Job Satisfaction Among Employee in Government Organizations in Iran".Journal of Basic and Applied Scientific Research, Vol. 4 No.1. pp: 217-229.

Peraturan Pemerintah RI Nomor 100 tahun 2000 tentang Pengangkatan PNS dalam Jabatan Struktural.

Peraturan Gubernur Provinsi DKI Jakarta Nomor 248 tahun 2014 tentang Organisasi dan Tata Kerja Kecamatan.

Pratiwi, Kurniasari dan Fathul Himam. (2014). "Kualitas Kehidupan Keja ditinjau dari Kepuasan Kerja dan Persepsi terhadap Kinerja". Jurnal Psikologi Undip: Vol. 13 No. 1, pp: 42-49

Rahmadiyani, Siska. (2012). Mutu Kehidupan Kerja Pegawai. chik 144.blogspot.co.id (diunduh pada 8 Agustus 2013).

Rivai, Veithzal dan Ella Jauvani Sagala. (2010). Manajemen Sumber Daya Manusia untuk Perusahaan: Dari Teori ke Praktik. Edisi 2. Rajawali Pers. Jakarta.

Robbins, Stephen P. (2008). Prilaku Organisasi. Cetakan Ketiga. Indonesia: Macananjaya Cemerlang.

Shah, Jamal Muhammad, Musawwir Ur Rehman, Gulnaz Akhatar, Huma Zafar dan Adnan Riaz. (2012). "Job Satisfaction and Motivation of Teacher of Public Educational Institutions". International Journal of Business and Social Science, Vol. 3 No. 8. pp: 271-281

Simanungkalit, V. Earnest. (2012)."Analisis Kualitas Kehidupan Kerja Industri Garmen di Indonesia". Tesis. Universitas Indonesia. Jakarta.

Simamora. (2004). Manajemen Sumber Daya Manusia. Yogyakarta: STIE YKPN.

Sinha, C. (2012). "Factors Affecting Quality of Work Life Empirical Evidence from Indian Organizations". Australian Journal of Business and Management Research, Vol. 11, pp: 31-40.

Sopiah.( 2008). Perilaku Organisasional. Andi. Yogyakarta.

Sugiyono.( 2008). Statistika Untuk Penelitian. Alfabeta. Bandung.

Sunaryo, Sinto dan Joko Suyono.(2013). "A Test of Model of the Relationship between Public Service Motivation, Job Satisfaction and Organization Citizenship Behavior". Review of Integrative Business and Economics Researchs, Vol. 2, pp: 384-398.

Umar, Aksal. (2015). "The Effect of Motivation and Career Development Against Employees Performance and Job Satisfaction of the Governor Office South Sulawesi Province, Indonesia". International Journal of Management Sciences, Vol.5 No.9, pp: 628-638.

Umar, Husein. (2010). Desain Penelitian MSDM dan Perilaku Karyawan. Rajawali Pers. Jakarta.

Widodo, E. Suparno. (2015). Manajemen Pengembangan Sumber Daya Manusia. Pustaka Pelajar. Yogyakarta.

Yang, Xingkun dan Weijie Wang. (2013). "Exploring the Determinants of Job Satisfaction of Civil Servants in Beijing, China". Public Personnel Management; Winter 2013;42, 4, pp: 566-587. 